Article

\title{
Nanoarchitectonics for High Adsorption Capacity Carboxymethyl Cellulose Nanofibrils-Based Adsorbents for Efficient $\mathrm{Cu}^{2+}$ Removal
}

\author{
Rongrong Si, Yehong Chen *, Daiqi Wang *, Dongmei Yu, Qijun Ding, Ronggang Li and Chaojun Wu *
}

Citation: Si, R.; Chen, Y.; Wang, D.; Yu, D.; Ding, Q.; Li, R.; Wu, C. Nanoarchitectonics for High Adsorption Capacity Carboxymethyl Cellulose Nanofibrils-Based Adsorbents for Efficient $\mathrm{Cu}^{2+}$ Removal. Nanomaterials 2022, 12, 160. https:// doi.org/10.3390/nano12010160

Academic Editor: Katsuhiko Ariga

Received: 9 December 2021 Accepted: 31 December 2021 Published: 3 January 2022

Publisher's Note: MDPI stays neutral with regard to jurisdictional claims in published maps and institutional affiliations.

Copyright: (C) 2022 by the authors. Licensee MDPI, Basel, Switzerland. This article is an open access article distributed under the terms and conditions of the Creative Commons Attribution (CC BY) license (https:// creativecommons.org/licenses/by/ $4.0 /)$.
State Key Laboratory of Biobased Material and Green Papermaking, Qilu University of Technology (Shandong Academy of Sciences), Jinan 250353, China; srr18238657108@163.com (R.S.); yudongmei197@163.com (D.Y.); xianshengding@qlu.edu.cn (Q.D.); lrg923@163.com (R.L.)

* Correspondence: chenyh@qlu.edu.cn (Y.C.); dqwang@126.com (D.W.); Chaojunwu2007@163.com (C.W.); Tel.: +86-15154115705 (Y.C.); +86-13176408628 (D.W.); +86-15069031483 (C.W.)

\begin{abstract}
In the present study, carboxymethyl cellulose nanofibrils (CMCNFs) with different carboxyl content $(0.99-2.01 \mathrm{mmol} / \mathrm{g})$ were prepared via controlling the ratio of monochloroacetic acid (MCA) and sodium hydroxide to Eucalyptus bleached pulp (EBP). CMCFs-PEI aerogels were obtained using the crosslinking reaction of polyethyleneimine (PEI) and CMCNFs with the aid of glutaraldehyde (GA). The effects of $\mathrm{pH}$, contact time, temperature, and initial $\mathrm{Cu}^{2+}$ concentration on the $\mathrm{Cu}^{2+}$ removal performance of CMCNFs-PEI aerogels was highlighted. Experimental data showed that the maximum adsorption capacity of CMCNF30-PEI for $\mathrm{Cu}^{2+}$ was $380.03 \pm 23 \mathrm{mg} / \mathrm{g}$, and the adsorption results were consistent with Langmuir isotherm $\left(\mathrm{R}^{2}>0.99\right)$. The theoretical maximum adsorption capacity was $616.48 \mathrm{mg} / \mathrm{g}$. After being treated with $0.05 \mathrm{M}$ EDTA solution, the aerogel retained an $85 \%$ removal performance after three adsorption-desorption cycles. X-ray photoelectron spectroscopy (XPS) results demonstrated that complexation was the main $\mathrm{Cu}^{2+}$ adsorption mechanism. The excellent $\mathrm{Cu}^{2+}$ adsorption capacity of CMCNFs-PEI aerogels provided another avenue for the utilization of cellulose nanofibrils in the wastewater treatment field.
\end{abstract}

Keywords: carboxymethylation; cellulose nanofibrils; aerogel; adsorption

\section{Introduction}

With the rapid development of the social economy, heavy metal pollution has become a thorny and crucial problem in modern society [1]. Anthropogenic activities such as mining, smelting, oil refining, and the manufacture of paint, release large amounts of these toxic and dangerous chemicals into the environment [2]. Of all kinds, $\mathrm{Cu}^{2+}$ is considered to be a major contaminant in water and can accumulate in the human liver, causing severe hemolysis and anemia. Therefore, the removal of $\mathrm{Cu}^{2+}$ from wastewater in an effective manner has become an important current issue [3].

There are many ways to solve the problem of heavy metal ion pollution in wastewater, mainly including chemical precipitation, ion exchange, ultrafiltration, flocculation, electrodialysis, adsorption, and reverse osmosis, etc. [4]. Among these methods, adsorption is very popular due to its high removal efficiency, flexibility in design, and low cost [5]. The adsorbents usually include activated carbon, clay, biochar, and polymers, etc. [6]. Although these adsorbents have high adsorption capacities for some heavy metal ions, they still present some disadvantages, such as unsatisfactory non-biodegradability, high cost of preparation or renewable energy, and secondary pollution. Therefore, it is necessary to find a kind of adsorbent with high adsorption capacity to solve this problem.

Recently, cellulose, as the most common structural amphiphilic renewable polymer resource in the biosphere, has been proven to have good adsorbent adsorption performance [7,8]. Many carboxylated nanocelluloses have been used in the removal of 
heavy metal ions, such as TO-CNF obtained by TEMPO oxidation [9], CNC obtained by $\mathrm{Fe}^{2+} / \mathrm{H}_{2} \mathrm{O}_{2}$ oxidation [10], and carboxymethylated nanocellulose [11]. Among them, carboxymethyl cellulose (CMCs), a cellulose derivative with a high carboxyl group content obtained by the alkalization and etherification of cellulose [8], is one of the most promising substrates for aerogels on account of its economic benefits and non-toxic natural polymers [11]. However, the abundant carboxymethyl groups make them very hydrophilic and thus limit their practical applications in aqueous environments. The separation of CMC-based adsorbents from water has become a difficult problem, and affects the regeneration and recycling of the adsorbent [12]. Therefore, it is an imperative problem to preparena CMC-based adsorbent which is stable in water and has cyclic performance. Assembling individual fibers into aerogel/hydrogel is a better way to easily separate from bulk solutions as aerogel consists of interconnected porous solid materials. Li et al. [11] used $\mathrm{Al}^{3+}$ as a crosslinking agent to obtain CMC-Al beads for removing heavy metal ions. As well, there are a few reports of combining CMC with other biological macromolecules for removing heavy metal ions, such as CMC-chitosan [13] and CMC-sodium alginate [14]. Li et al. [15] obtained the NFC solution through TEMPO oxidation, and then achieved physically crosslinked network NFC/PEI composite hydrogel (NPH) through electrostatic combination with PEI (polyethyleneimine) solutions, which showed good adsorption effect for $\mathrm{Cu}^{2+}$ and $\mathrm{Pb}^{2+}$. However, rare studies have reported on grafted PEI with CMCNFs.

Branched PEI has plenty of amino groups, and usually were selected to fabricate adsorbents [16]. In this article, CMCFs-PEI aerogels were obtained using the crosslinking reaction of polyethyleneimine (PEI) and CMCNFs with different carboxyl content. Furthermore, their $\mathrm{Cu}^{2+}$ removal performance was systematically investigated under different conditions. After that, the removal mechanism of $\mathrm{Cu}^{2+}$ removal was demonstrated using FTIR (Fourier transform infrared spectroscopy) and XPS analysis. The adsorption and desorption characteristics of the aerogel were also detected.

\section{Experimental}

\subsection{Methods and Materials}

Materials: Eucalyptus bleached pulp (EBP, Jinan, Shandong Province, China), sodium hydroxide (NaOH, AR grade, Jinan, Shandong Province, China), monochloroacetic acid (MCA, Jinan, Shandong Province, China), anhydrous methanol(Jinan, Shandong Province, China), glutaraldehyde (GA, 50\% in water, Aladdin), PEI (polyethylenrimine, $70000 \mathrm{Mw}$, Macklin), copper nitrate $\left(\mathrm{Cu}\left(\mathrm{NO}_{3}\right)_{2}(1000 \mathrm{mg} / \mathrm{L})\right.$, Beijing, China), hydrochloric acid $(\mathrm{HCl}$, $37 \%$, Jinan, Shandong Province, China), ethylenediaminetetraacetic acid (EDTA, Jinan, Shandong Province, China).

\subsection{Preparation of Carboxymethyl Cellulose Nanofibers (CMCNFs) Dispersions}

During the reaction, the quality ratio of eucalyptus bleached pulp (EBP) to $\mathrm{NaOH}$ was 1:1 $(w / w)$. In order to obtain CMCNFs dispersions with different carboxylate contents, reagents with different MCA $(10,20,30 \mathrm{~g})$ were selected.

First, dry weight EBP (20 g) was blended with $100 \mathrm{~mL} \mathrm{NaOH}$ solution $(5 \mathrm{~mol} / \mathrm{L})$ in a sealed bag and the mixture was vigorously rubbed at room temperature for one hour. The MCA solution (40\% MCA/deionized water $w / v)$ was put in a sealed bag slowly and heated it to $65{ }^{\circ} \mathrm{C}$ for $2 \mathrm{~h}$. The treated wood fibers are then repeatedly rinsed with the ethanol mixture until the $\mathrm{pH}$ of the filtrate was neutral. After that, the carboxymethylated EBP was treated with a high pressure homogenizer. The samples were denoted as CMCNF10, 20, 30 $(10,20,30$ were the amount of MCA).

\subsection{Preparation of CMCNFs-PEI Aerogel}

A total of $50 \mathrm{~mL} \mathrm{CMCNFs} \mathrm{suspension}(0.5 \mathrm{wt} \%)$ reacted with $50 \mathrm{~mL} \mathrm{GA}(0.5 \%)$ solution at $50{ }^{\circ} \mathrm{C}$ for $0.5 \mathrm{~h}$ to crosslinked CMCNFs and GA. Subsequently, $50 \mathrm{~mL}$ of PEI solution $(2 \%$ in water) was added to the mixture. After mixing and stirring for $10 \mathrm{~min}$, the product was 
centrifuged and washed thoroughly with deionized water 3 times, and then freeze-dried to obtain CMCNFs-PEI aerogel.

\subsection{Characterization}

Both wood fibers, CMCNFs (freeze-dried aerogel) and CMCNFs-PEI aerogels, were characterized by FTIR (Prestige21, Shimadzu Corporation, Karlsruhe, Germany). The content of carboxylate in CMCNFs was determined by standard conductance titration (DDSJ-319L, Shanghai, China). The morphology of CMCNFs was characterized by atomic force microscope (AFM, Brooker, Karlsruhe, Germany). Scanning electron microscope (SEM, Regulus 8220, Tokyo, Japan) was used to observe the form of CMCNFs-PEI aerogel. The crystalline structure of EBP and CMCNFs was measured by X-ray diffraction (XRD, Bruker, Karlsruhe, Germany). The carboxyl content of the prepared CMCNFs was determined by conductivity meter (DDSJ-318, Shanghai, China). Thermogravimetric analysis (TGA) of CMCNFs was performed using a synchronous thermal analyzer (STA449, Selb, Germany) under inert $\left(\mathrm{N}_{2}\right)$ atmosphere heated continuously from room temperature (RT) at $10^{\circ} \mathrm{C} / \mathrm{min}$ to $600{ }^{\circ} \mathrm{C}$. Besides, X-ray photoelectron spectroscopy (XPS, ESCALABXi+, New York, NY, USA) was analyzed for the surface chemical compositions of CMCNF30-PEI aerogel and CMCNF30-PEI loaded $\mathrm{Cu}^{2+}$.

\subsection{Adsorption Experiments for $\mathrm{Cu}^{2+}$ Adsorption by Three Aerogels}

The adsorption kinetics and isotherms of $\mathrm{Cu}^{2+}$ by CMCFs-PEI were investigated by batch adsorption experiments. Add aerogels $(0.05 \mathrm{~g})$ and $\mathrm{Cu}^{2+}$ solution $(50 \mathrm{~mL})$ to a $100 \mathrm{~mL}$ flask. Then put the flask in Temersionoxcillator registrarion (NoKi) at $25{ }^{\circ} \mathrm{C}$ to reach the adsorption equilibrium. When the $\mathrm{pH}$ exceeded $6.5, \mathrm{Cu}^{2+}$ ions could be converted to $\mathrm{Cu}$ $(\mathrm{OH})_{2}$ precipitation [14]. The effect of initial $\mathrm{pH}$ values in the range of 2-6 was investigated, in which the $\mathrm{pH}$ of the $\mathrm{Cu}^{2+}$ solution was controlled by $1 \mathrm{M} \mathrm{NaOH} / 1 \mathrm{M} \mathrm{HCl}$ solution. For the kinetics study, the effect of contact time from 0 to $8 \mathrm{~h}$ was investigated at optimal $\mathrm{pH}$. The adsorption isotherm experiments were carried out in the concentration range of $20 \sim 400 \mathrm{mg} / \mathrm{L}$ metal ions. The residual concentration of $\mathrm{Cu}^{2+}$ were determined by flame atomization atomic absorption spectrometry (AAS, GGX-600, China), the equilibrium adsorption capacity $\left(q_{e}\right.$, $\mathrm{mg} / \mathrm{g}$ ) and removal rate were calculated according to (Equation (1)) [17].

$$
\begin{gathered}
q_{e}=\frac{\left(C_{0}-C_{e}\right) \times V}{m} \\
R=\frac{\left(C_{0}-C_{e}\right)}{C_{0}} \times 100 \%
\end{gathered}
$$

where $C_{0}$ is the initial concentration of $\mathrm{Cu}^{2+}(\mathrm{mg} / \mathrm{L})$ and $C_{e}$ is the concentration of $\mathrm{Cu}^{2+}$ at equilibrium time; $V(\mathrm{~mL})$ is the volume of the solution and $m(\mathrm{mg})$ is the aerogel dose.

\subsection{Adsorption Kinetics and Isotherms}

Pseudo-first-order and second-order kinetic models were used to simulate the adsorption kinetic data of $\mathrm{Cu}^{2+}$ on CMCNFs-PEI, and the expression is found in Equations (3) and (4) [18]:

$$
\begin{gathered}
\log \left(q_{e}-q_{t}\right)=\log q_{e}-\frac{k_{1} t}{2.303} \text { or } \ln \left(q_{e}-q_{t}\right)=\ln q_{e}-k_{1} t \\
\frac{t}{q_{t}}=\frac{1}{k_{2} q_{e}^{2}}+\left(\frac{1}{q_{e}}\right) t
\end{gathered}
$$

where $q_{t}$ is the adsorption capacity after time $t$ and $q_{e}$ is the saturated adsorption capacity of $\mathrm{Cu}^{2+} ; k_{1}\left(\mathrm{~min}^{-1}\right)$ and $k_{2}(\mathrm{~g} /(\mathrm{mg} \mathrm{min}))$ are rate constants of pseudo-first- and second-order kinetics, respectively. 
The adsorption isotherms of $\mathrm{Cu}^{2+}$ adsorption by CMCNFs-PEI aerogel; the Langmuir and Freundlich adsorption isotherm models were used to analyze the experimental data, which are represented as Equations (5) and (6) [19]:

$$
\begin{gathered}
\frac{C_{e}}{Q_{e}}=\frac{C_{e}}{Q_{m}}+\frac{1}{Q_{m} b} \\
\lg Q_{e}=\lg K_{f}+\frac{1}{n} \lg C_{e}
\end{gathered}
$$

where $Q_{e}(\mathrm{mg} / \mathrm{g})$ is the equilibrium adsorption capacity, $C_{e}(\mathrm{mg} / \mathrm{L})$ is the $\mathrm{Cu}^{2+}$ solution concentration at equilibrium, $Q_{m}(\mathrm{mg} / \mathrm{g})$ is the maximum adsorption capacity and $b$ is the Langmuir adsorption constant related to adsorption energy, $K_{f}$ and $n$ are the Freundlich adsorption constants which indicate the capacity and intensity of the adsorption, respectively.

Thermodynamic parameters such as free energy, enthalpy change and entropy change are determined by thermodynamic equations, as follows (7) and (8) [20]:

$$
\begin{gathered}
\operatorname{Ln}\left(K_{d}\right)=\frac{-\Delta \mathrm{H}}{\mathrm{RT}}+\frac{\Delta S}{R} \\
\Delta \mathrm{G}=\Delta \mathrm{H}-\mathrm{T} \Delta \mathrm{S}
\end{gathered}
$$

where $K_{d}(\mathrm{~mL} / \mathrm{g})$ is the equilibrium constant, $R$ is the gas constant $(8.314 \mathrm{~J} / \mathrm{mol} / \mathrm{K})$, and $T$ $(K)$ is the absolute temperature.

\subsection{Cycle Testing of $\mathrm{CMCNF}_{S}-\mathrm{PEI}$}

In order to evaluate the cycling stability of the aerogel, the adsorption-desorption cyclic experiments were carried out. $\mathrm{Cu}^{2+}$ was adsorbed by CMCNF30-PEI aerogel, then immersed in $0.05 \mathrm{M}$ EDTA solution and stirred at $25^{\circ} \mathrm{C}$ for $3 \mathrm{~h}$ to remove $\mathrm{Cu}^{2+}$. The aerogel was then immersed in distilled water several times to elute all the salt until a pH of about 7 was reached before another adsorption process was carried out.

\section{Results and Discussion}

\subsection{Characterization of the Aerogel}

The FTIR spectra of EBP, CMCNFs, and CMCNFs-PEI are presented in Figure 1a. A comparison of the FTIR results reveals that new peaks appeared in CMCNFs after carboxymethylation. For EBP, the peak at $3400 \mathrm{~cm}^{-1}$ corresponds to the stretching vibration of $\mathrm{O}-\mathrm{H}$ groups, and the peak at $1370 \mathrm{~cm}^{-1}$ and $1322 \mathrm{~cm}^{-1}$ belong to $\mathrm{C}-\mathrm{H}$ vibration [21], whereas in the FTIR spectra of the CMCNF10 sample, the stretching vibration of the carbonyl $(\mathrm{C}=\mathrm{O})$ present in the carboxylate groups $\left(\mathrm{COO}^{-}\right)$was observed at $1606 \mathrm{~cm}^{-1}$. However, CMCNF20 and CMCNF30 have a stretching vibration at $1740 \mathrm{~cm}^{-1}(-\mathrm{COOH})$, which may be due to higher carboxyl content. To prove the successful grafting of PEI onto CMCNFs, the FTIR spectra of CMCNFs-PEI aerogels are shown in Figure 1b. Compared to CMCNFs, there are many new adsorption peaks appearing at $1453 \mathrm{~cm}^{-1}, 1592 \mathrm{~cm}^{-1}$, and $1648 \mathrm{~cm}^{-1}$ associated with the amino groups on CMCNFs-PEI aerogels. Also, the occurrence of $-\mathrm{CH}_{2}$ - stretching vibrations at $2923 \mathrm{~cm}^{-1}$ and $2848 \mathrm{~cm}^{-1}$ also can prove it. The adsorption peak at $1740 \mathrm{~cm}^{-1}$ should be contributed from stretching $\mathrm{C}=\mathrm{O}$ groups, which appeared in three CMCNFs-PEI aerogels. 

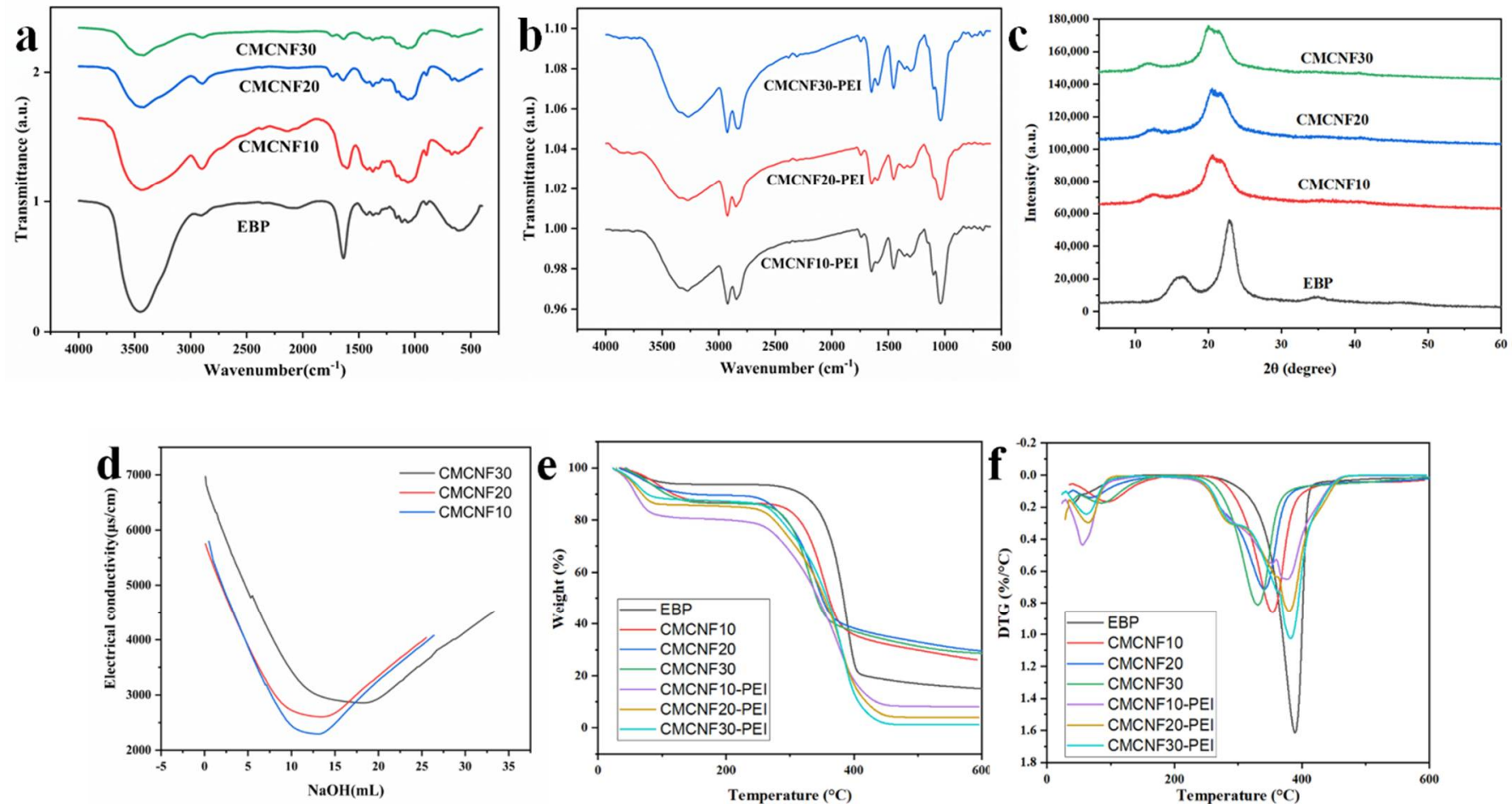

Figure 1. FTIR spectra of (a) EBP, CMCNFs, (b) CMCNFs-PEI, (c) XRD spectra of EBP and CMCNFs, (d) illustration of approach used for determination of carboxyl group in CMCNFs, (e) TGA, and (f) DTG curves of all samples.

The XRD was used to analyze the effect of carboxymethylation on the crystal structure of CMCNFs (Figure 1c). Three peaks were observed at $2 \theta=15.72^{\circ}, 22.5^{\circ}$, and $34.5^{\circ}$ in EBP. This is representative of EBP which is typical of cellulose I. For CMCNFs, the $2 \theta=22.5^{\circ}$ diffraction peak disappeared, and the $2 \theta=20.5^{\circ}$ diffraction peak corresponding to the alkali cellulose became obvious. At $2 \theta=15.72^{\circ}$, the diffraction peak became weak and disappeared at $2 \theta=34.5^{\circ}$. After treatment with $5 \mathrm{~mol} / \mathrm{L} \mathrm{NaOH}$ solution, the crystal lattice changed greatly, which is called intracellular swelling. There are two kinds of intracellular swelling. One is where the solvent enters the intracellular cell and increases the distance between macromolecular chains of cellulose, which is also called separate swelling. The other involves the formation of a compound with cellulose, which then changes the cellular structure of cellulose, and the cellular structure of primary cellulose is transformed into the crystalline structure of alkali cellulose [22].

The thermal degradation onset temperature $\left(\mathrm{T}_{0}\right)$ and maximum decomposition temperature $\left(\mathrm{T}_{\max }\right)$ are shown in Table 1 . During the process from RT to $100{ }^{\circ} \mathrm{C}$, due to the loss of water, the four substances have a slight quality degradation. The $\mathrm{T}_{0}$ and $\mathrm{T}_{\max }$ of the EBP were about 276.5 and $388.78{ }^{\circ} \mathrm{C}$, respectively; thus, the CMCNFs exhibited a lower $\mathrm{T}_{0}$ and $\mathrm{T}_{\text {max }}$. The $\mathrm{NaOH} /$ chloroacetic acid system introduced a large amount of carboxyl groups, and at neutral $\mathrm{pH}$, the hydrogen bonds were disrupted and the molecular chains became less constrained. A higher carboxyl content lowered the $\mathrm{T}_{0}$ and $\mathrm{T}_{\max }$, for example, $\mathrm{T}_{0}$ and $\mathrm{T}_{\max }$ of CMCNF30 (232.96 and $330.78{ }^{\circ} \mathrm{C}$ ) was lower than that of CMCNF10 (267.99 and $\left.353.76{ }^{\circ} \mathrm{C}\right)$. The carboxyl group on the surface of the CNCNFs increased, and the thermal stability gradually decreased because of the more thermally unstable carboxyl groups insertion of the CNF surfaces. The more the carboxyl groups on the nanofibrils, the lower the $\mathrm{T}_{0}$ and $\mathrm{T}_{\max }$. 
Table 1. Thermal stability parameters of EBP and CMCNFs.

\begin{tabular}{cccccccc}
\hline & EBP & CMCNF10 & CMCNF20 & CMCNF30 & CMCNF10-PEI & CMCNF20-PEI & CMCNF30-PEI \\
\hline $\begin{array}{c}\text { Carboxyl content } \\
(\mathrm{mmol} / \mathrm{g})\end{array}$ & & 0.99 & 1.52 & 2.01 & & & \\
$\mathrm{~T}_{0}\left({ }^{\circ} \mathrm{C}\right)$ & 276.5 & 267.99 & 225.71 & 232.96 & 218.64 & 219.60 & 218.19 \\
$\mathrm{~T}_{\max }\left({ }^{\circ} \mathrm{C}\right)$ & 388.78 & 353.76 & 340.49 & 330.78 & 380.09 & 380.36 & 381.50 \\
\hline
\end{tabular}

$\mathrm{T}_{0}, \mathrm{~T}_{\max }$ were calculated from TGA curves.

The surface morphology of CMCNFs was examined by AFM (Figure 2a-c) and CMCNFs-PEI was examined by SEM (Figure $2 \mathrm{~d}-\mathrm{f}$ ). As a result, it can be clearly seen that there is a larger aspect ratio. From the SEM of $\mathrm{CMCNF}_{\mathrm{S}}-\mathrm{PEI}$ aerogel, it can be seen that there are pore structures in the typical 3D network. This can be used as a transport channel for heavy metal ions from the aqueous medium to enter the interior of the aerogel network through the rich pore structure. At the same time, it can also improve contact chance of $\mathrm{Cu}^{2+}$ with CMCNFs-PEI aerogel. When the adsorbent contacts the wastewater, water molecules can penetrate into the interior as soon as possible to achieve the effect of rapid adsorption. It may be that the water solubility of CMCNF30 increased with the increase of carboxyl group content, leading to the different surface morphology of CMCNF30-PEI. Compared with other heavy metal adsorbents, this aerogel has attracted extensive attention in the field of water treatment due to its unique 3D structure.
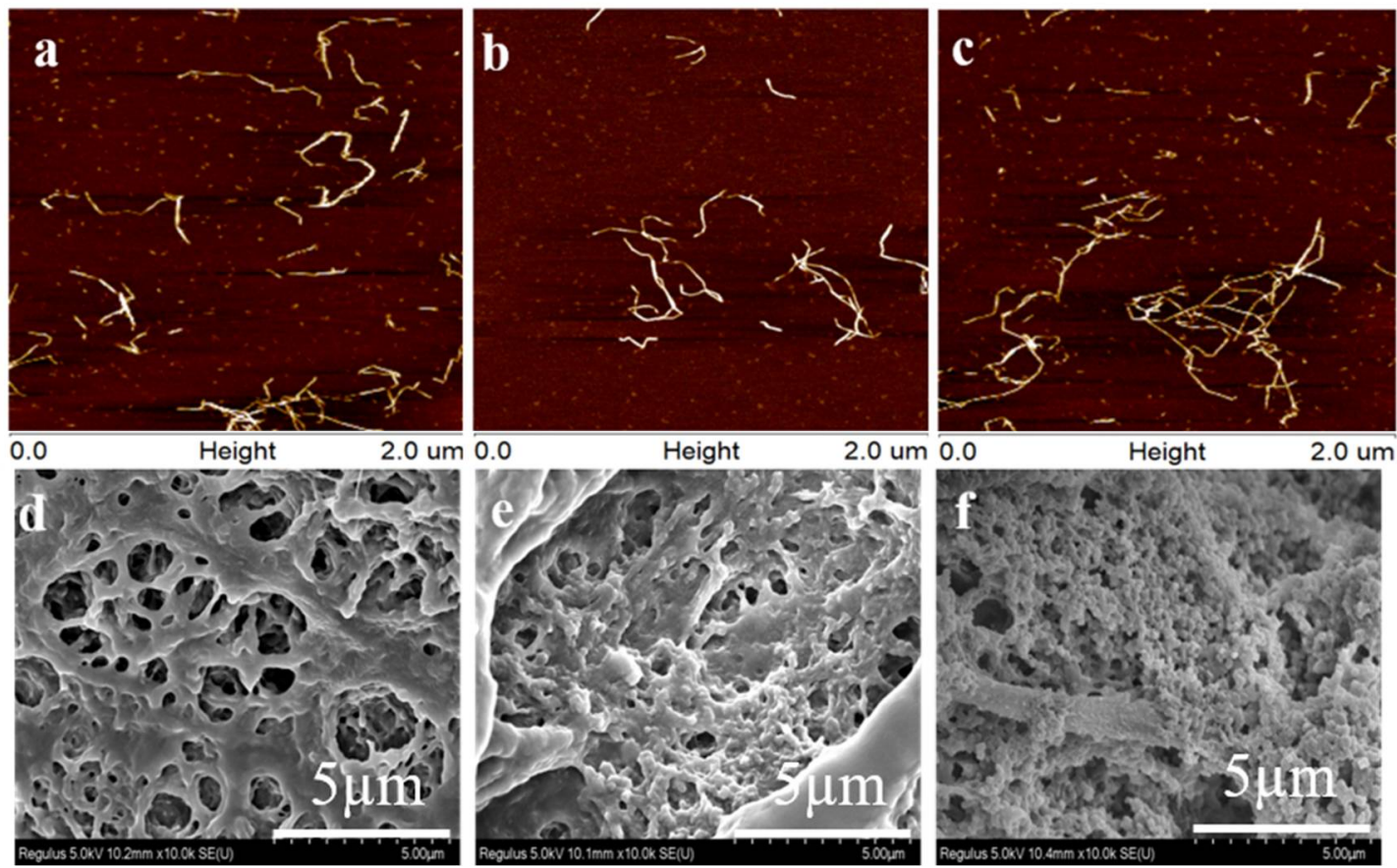

Figure 2. AFM images for dispersions of (a) CMCNF10, (b) CMCNF20, (c) CMCNF30; SEM images for aerogel of (d) CMCNF10-PEI, (e) CMCNF20-PEI, (f) CMCNF30-PEI.

A total of $0.03 \mathrm{~g}$ of CMCNF30 aerogel obtained by freeze drying of CMCNF30 suspension was weighed and placed into $20 \mathrm{~mL}$ of deionized water for a hydrophilicity test. As shown in Figure 3, from the appearance, the color of CMCNF30 aerogel is white. After PEI modification, the color of CMCNF30/PEI aerogel turned yellow due to Schiff base reaction. CMCNF30/PEI aerogel of the same quality was used for comparison. The volume of both CMCNF30 and CMCNF30/PEI aerogels increased due to water absorption one minute after the aerogels were placed in deionized water. After $12 \mathrm{~h}, \mathrm{CMCNF30}$ aerogel dissolved in water, however, CMCNF30/PEI aerogel did not changed. This proves that the hydrophilicity of CMCNF decreases after PEI modification. 


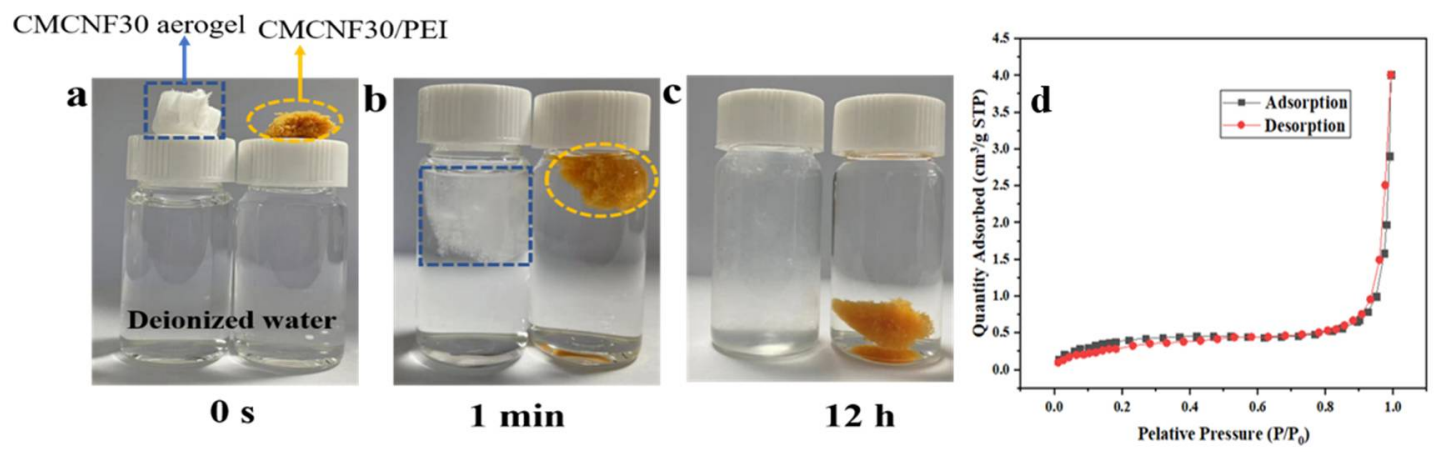

Figure 3. CMCNF30 and CMCNF30/PEI aerogel in deionized water for (a) $0 \mathrm{~s}$, (b) $1 \mathrm{~min}$, (c) $12 \mathrm{~h}$; (d) adsorption-desorption isotherm of CMCNF30-PEI aerogel at 77K.

Figure $3 \mathrm{~d}$ shows the $\mathrm{N}_{2}$ adsorption-desorption curve of the sample at a temperature of $77 \mathrm{~K}$. The curve of CMCNF30-PEI aerogel shown in the figure is type four, which also verifies that the nanoparticles have a mesoporous structure. As can be seen from Table 2, the specific surface area and average pore size of CMCNF10-PEI increased from 0.82 to $1.52 \mathrm{~m}^{2} / \mathrm{g}$, and the average pore size increased from 92.85 to $163.3 \AA$. The adsorption of $\mathrm{P} / \mathrm{P}_{0}$ between $0-0.6$ representing micropore $(<20 \AA)$ is negligible. The adsorption then increased rapidly, when $\mathrm{P} / \mathrm{P}_{0}$ was between $0.6-1.0$, representing mesoporous structures (20-500 $\AA$ ) and indicating the presence of mesopores in CMCNF30-PEI, which provided a positive effect for the adsorption of heavy metals.

Table 2. Specific surface area and average pore size of CMCNFs-PEI aerogel.

\begin{tabular}{|c|c|c|c|}
\hline Sample & $\begin{array}{l}\text { Bet Surface Area } \\
\left(\mathrm{m}^{2} / \mathrm{g}\right)\end{array}$ & $\begin{array}{c}\text { Langmuir Surface } \\
\text { Area }\left(\mathrm{m}^{2} / \mathrm{g}\right)\end{array}$ & Pore Size (Å) \\
\hline CMCNF10-PEI & 0.82 & 0.21 & 92.85 \\
\hline CMCNF20-PEI & 1.16 & 1.55 & 121.8 \\
\hline CMCNF30-PEI & 1.52 & 2.15 & 163.3 \\
\hline
\end{tabular}

\section{2. $\mathrm{Cu}^{2+}$ Adsorption}

\subsubsection{Adsorption Kinetics of CMCNFs-PEI Aerogel}

We attempted to understand the $\mathrm{Cu}^{2+}$ removal performance of CMCNFs-PEI with $\mathrm{pH}$ and time. As presented in Figure $4 \mathrm{a}-\mathrm{c}$, due to the presence of amino groups on CMCNFs-PEI, the surface charge changes with the change of $\mathrm{pH}$, thereby affecting the adsorption capacity. With the increase of $\mathrm{pH}$, adsorption capacity also increases. Owing to the protonation of amino groups, the absorbent showed low adsorption capacity to $\mathrm{Cu}^{2+}$ at low $\mathrm{pH}$ conditions. When at a $\mathrm{pH}$ of six, the adsorption capacity increased to the maximum. It is noticeable that the adsorption capacity of aerogels increases as the carboxyl content of aerogels increases. According to the experimental data, the content of CMCNF10-PEI increased from 15.26 to $18.67 \mathrm{mg} / \mathrm{g}$ for CMCNF30-PEI. Therefore, the adsorption performance of CMCNFs-PEI for $\mathrm{Cu}^{2+}$ was studied under the condition of a $\mathrm{pH}$ of six.

To understand the basic kinetics of $\mathrm{Cu}^{2+}$ removal by CMCNFs-PEI, we evaluated the relationship between contact time $(t)$ and removal capacity $\left(Q_{t}\right)$ between exposure time 0 to $540 \mathrm{~min}$ (Figure $4 \mathrm{~d}, \mathrm{e}$ ). The removal rate increased rapidly at the beginning of the experiment and then reached equilibrium after $120 \mathrm{~min}$. Two simplified kinetic models can be used to fit the experimental data of the adsorption process. The fitting results of adsorption kinetics for $\mathrm{Cu}^{2+}$ ion adsorption by CMCNFs-PEI aerogels is exhibited in Table 2. The non-linear correlation coefficient $\left(R^{2}\right)$ values for the second-order are higher than first-order, which indicates that the $\mathrm{Cu}^{2+}$ removal by CMCNFs-PEI is a rate-limiting and chemisorption process. 

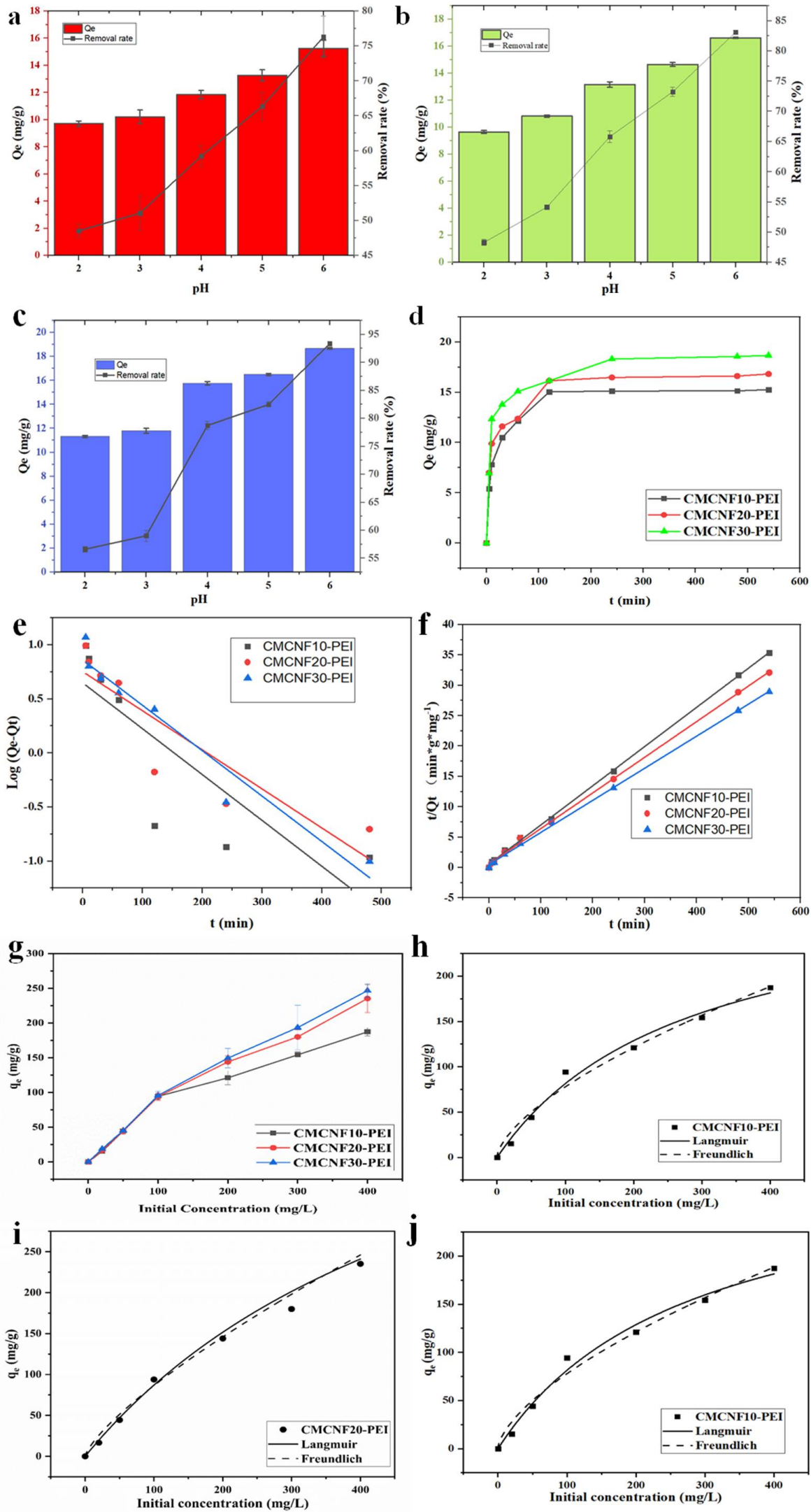

Figure 4. Effect of initial $\mathrm{pH}$ on $\mathrm{Cu}^{2+}$ adsorption; (a) CMCNF10-PEI (b) CMCNF20-PEI (c) CMCNF30PEI. (d) Contact time removal capacity for $\mathrm{Cu}^{2+}$ adsorption $\left(\mathrm{pH}=6, \mathrm{C}_{0}=20 \mathrm{mg} / \mathrm{L}, \mathrm{T}=25^{\circ} \mathrm{C}\right.$ ). (e) Plots of pseudo-first-order, and (f) pseudo-second-order of CMCNF10-PEI, CMCNF20-PEI, CMCNF30-PEI. (g) Effect of different initial concentration on $\mathrm{Cu}^{2+}$ adsorption of three CMCNFs-PEI $(\mathrm{pH}=6, t=24 \mathrm{~h}$, $T=25^{\circ} \mathrm{C}$ ). (h) CMCNF10, (i) CMCNF20-PEI, (j) CMCNF30-PEI isotherm model for $\mathrm{Cu}^{2+}$ adsorption. 


\subsubsection{Adsorption Isotherms of CMCNFs-PEI Aerogel}

In order to confirm the interaction between CMCNFs-PEI and $\mathrm{Cu}^{2+}$, and that the maximum adsorption capacity of CMCNFs-PEI is the key to evaluate its removal performance, we studied the relationship between the initial $\mathrm{Cu}^{2+}$ concentration and equilibrium removal capacity of CMCNFs-PEI.

The removal results of the CMCNFs-PEI with different initial concentrations of $\mathrm{Cu}^{2+}$ are shown in Figure 4g-i. The adsorption isotherm parameters are displayed in Table 3. For CMCNF10-PEI, $R^{2}>0.98$; for other adsorbents (CMCNF20-PEI, CMCNF30-PEI), $R^{2}>0.99$. The results show that both Langmuir and Freundlich models can fit the adsorption isotherm well. The Langmuir model showed that the active adsorption sites were uniformly distributed on the surface of the aerogel, and the adsorption of $\mathrm{Cu}^{2+}$ ions occurred at the binding sites of functional groups and the surface, forming a monolayer [22]. However, Freundlich isotherm is used in the low to intermediate adsorbate concentration range [23]. The maximum Langmuir adsorption capacity for $\mathrm{Cu}^{2+}$ on CMCNF10-PEI aerogel was determined to be $307.43 \mathrm{mg} / \mathrm{g}$. The adsorption capacity increased with the increase of carboxyl group content. The maximum adsorption capacity of CMCNF30-PEI was $616.48 \mathrm{mg} / \mathrm{g}$, which was considered to be a super high capacity. This may be due to the carboxyl group and the amino group acting as electrostatic attraction and chelation to $\mathrm{Cu}^{2+}$, respectively. In Figure $5 b$, we provide a comparison between the current CMCNFs-PEI aerogels and other related $\mathrm{Cu}^{2+}$ adsorbents presented in the literatures. Compared with previous reported results, the adsorption ability of CMCNFs-PEI aerogels for $\mathrm{Cu}^{2+}$ are much higher.

Table 3. Kinetic and isotherm parameters for $\mathrm{Cu}^{2+}$ adsorption onto CMCNFs-PEI aerogels.

\begin{tabular}{ccccc}
\hline \multirow{2}{*}{ Model } & Parameters & \multicolumn{3}{c}{ Aerogels } \\
\cline { 3 - 5 } & & CMCNF10-PEI & CMCNF20-PEI & CMCNF30-PEI \\
\hline \multirow{3}{*}{ 1st-order kinetic } & $k_{1}(\mathrm{~g} / \mathrm{mg} \cdot \mathrm{h})$ & 0.063 & 0.096 & 0.1086 \\
& $q_{\text {exp }}(\mathrm{mg} / \mathrm{g})$ & 15.26 & 16.62 & 18.67 \\
& $q_{\text {cal }}(\mathrm{mg} / \mathrm{g})$ & 14.50 & 15.31 & 16.99 \\
& $R^{2}$ & 0.9470 & 0.9060 & 0.9387 \\
\hline \multirow{2}{*}{ 2nd-order } & $k_{2}(\mathrm{~g} / \mathrm{mg} \cdot \mathrm{h})$ & 0.0059 & 0.0074 & 0.0078 \\
kinetic & $q_{\text {exp }}(\mathrm{mg} / \mathrm{g})$ & 15.26 & 16.62 & 18.67 \\
& $q_{\text {cal }}(\mathrm{mg} / \mathrm{g})$ & 15.51 & 16.48 & 18.18 \\
& $R^{2}$ & 0.9874 & 0.9652 & 0.9745 \\
Langmuir & $K_{L}(\mathrm{~L} / \mathrm{g})$ & 0.0036 & 0.0019 & 0.0013 \\
isotherm & $q_{0}(\mathrm{mg} / \mathrm{g})$ & 307.43 & 528.36 & 616.48 \\
& $R^{2}$ & 0.9845 & 0.9915 & 0.9972 \\
\hline \multirow{2}{*}{ Freundlich } & $K_{F}$ & 82.07 & 62.18 & 114.02 \\
isotherm & $n$ & 4.13 & 2.74 & 5.74 \\
& $R^{2}$ & 0.9843 & 0.9933 & 0.9845 \\
\hline
\end{tabular}

\subsubsection{Thermodynamics of CMCNF30-PEI Adsorption}

Thermodynamic parameters associated with the adsorption of $\mathrm{Cu}^{2+}$ using CMCNF30PEI are presented in Figure $5 \mathrm{~b}$ and Table 4 . In this section, the adsorption capacity and removal efficiency of CMCNF30-PEI at a $\mathrm{pH}$ of six and the initial $\mathrm{Cu}^{2+}$ concentration of $20 \mathrm{mg} / \mathrm{L}$ at different temperatures $(288,298$ and $308 \mathrm{~K})$ were investigated. It can be seen from the figure that with the increase of temperature, both adsorption capacity and removal efficiency increase. $\Delta \mathrm{G}>0$ and decreases with the increase of temperature, indicating the increasing spontaneity of the adsorption. Therefore, the adsorption of $\mathrm{Cu}^{2+}$ using the aerogel appears to be an irreversible and spontaneous endothermic process. 

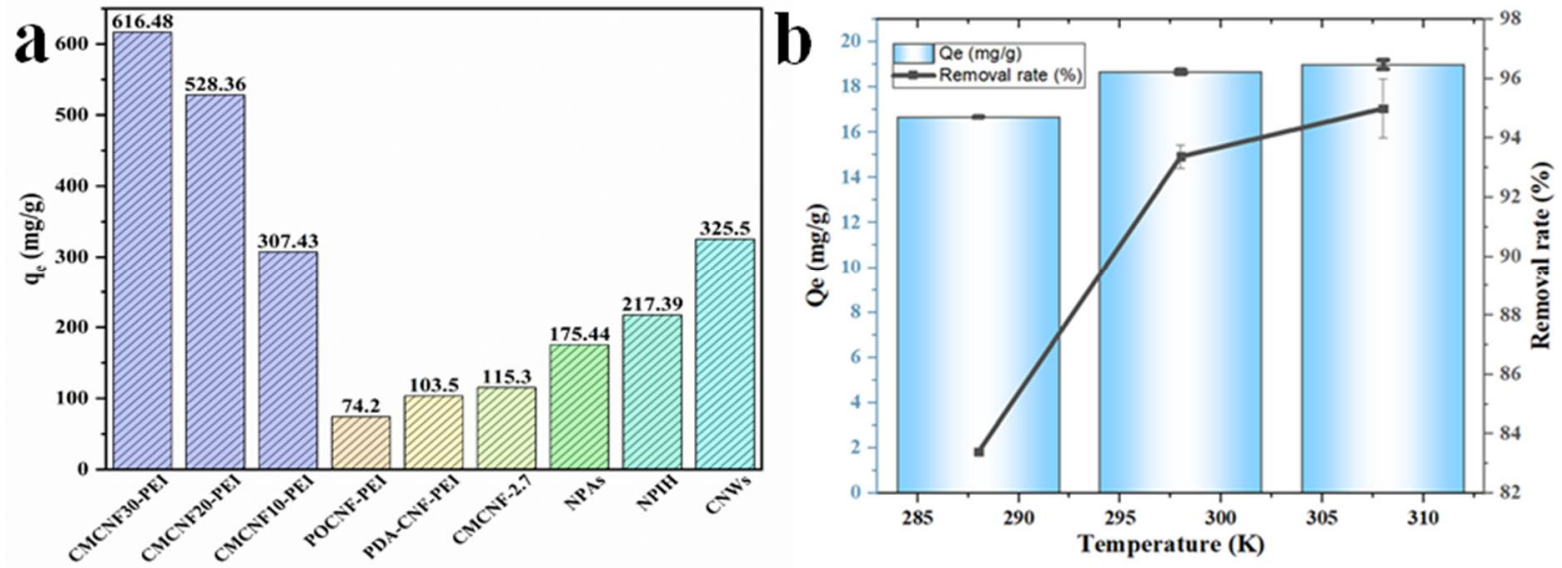

Figure 5. (a) The maximum adsorption capacity for $\mathrm{Cu}^{2+}$ with different cellulose-based adsorbents was compared with CMCNFs-PEI aerogels: $\mathrm{Cu}^{2+}$ adsorption capacity in this work, pomelo peel carboxylated cellulose nanofibers-PEI (POCNF-PEI) [24]; polydopamine-CNF-PEI (PDA-CNF-PEI) [25]; carboxymethylated CNFs (CMCNF-2.7) [26]; NFC/PEI composite aerogel (NPAs) [15]; NFCs/poly(2(dimethylamino) ethyl methacrylate) interpenetrating network hydrogels (NPIHs) [27]; cellulose nanowhiskers (CNWs) [28]. (b) Effect of temperature on the $\mathrm{Cu}^{2+}$ adsorption of CMCNF30-PEI.

Table 4. Thermodynamic parameters of CMCNF30-PEI adsorption for $\mathrm{Cu}^{2+}$.

\begin{tabular}{cccc}
\hline $\mathbf{T}(\mathbf{K})$ & $\Delta \mathrm{G}(\mathrm{KJ} / \mathbf{m o l})$ & $\Delta \mathbf{H}(\mathbf{K J} / \mathbf{m o l})$ & $\Delta \mathbf{S}(\mathrm{KJ} / \mathbf{m o l} / \mathbf{K})$ \\
\hline 288 & -20.6 & & \\
298 & -23.02 & 49.33 & 0.2428 \\
308 & -25.45 & & \\
\hline
\end{tabular}

\subsubsection{Adsorption Mechanism of CMCNFs-PEI on $\mathrm{Cu}^{2+}$}

XPS was used to study the elemental composition of CMCNF30-PEI and CMCNF30PEI loaded $\mathrm{Cu}^{2+}$ ions (Figure 6a-h). Obviously, several new peaks appeared, assigned to $\mathrm{Cu} 2 \mathrm{p}$ doublet $\left(\mathrm{Cu} 2 \mathrm{p}_{1 / 2}\right.$ and $\left.\mathrm{Cu} 2 \mathrm{p}_{3 / 2}\right), \mathrm{Cu} 3 \mathrm{~s}$, and $\mathrm{Cu} 3 \mathrm{p}$, which confirms the presence of $\mathrm{Cu}^{2+}$ on CMCNF30-PEI. In addition, the detailed XPS spectra of different elements at high resolution were deconvolved to evaluate the contribution of each component. As shown in Figure $6 \mathrm{~b}$, before adsorption, the $\mathrm{N}$ 1s peak could be fitted into the three components of $398.15,399$, and $400.15 \mathrm{eV}$ corresponding to $-\mathrm{N}-,-\mathrm{NH}-$ and $-\mathrm{NH}_{2}$, respectively. The high resolution XPS O 1s core-level spectrum of CMCNF30-PEI (Figure 6c) can be divided into two components at $530.5 \mathrm{eV}$ and $531.8 \mathrm{eV}$, which were assigned to $\mathrm{C}-\mathrm{O}$ and $\mathrm{C}=\mathrm{O}$, respectively. After $\mathrm{Cu}^{2+}$ ions were adsorbed (Figure 6f), the peaks of $\mathrm{N} 1 \mathrm{~s}$ shifted to $398.7 \mathrm{eV}, 399.3 \mathrm{eV}$, and $401.3 \mathrm{eV}$, and proved that all three amino groups are involved in the binding of $\mathrm{Cu}^{2+}$ ions [29]. At the same time, a new peak of $406.1 \mathrm{eV}$ appeared in the $\mathrm{N}$ 1s spectra, which was due to the nitrogen in the amino groups sharing a lone electron pair to form the metal complex. In Figure $6 \mathrm{~g}$, for the O 1s spectra of CMCNF30-PEI aerogel, the $\mathrm{C}-\mathrm{O}$ and $\mathrm{C}=\mathrm{O}$ components increased to $532.9 \mathrm{eV}$ and $531.5 \mathrm{eV}$, which is due to the electrons in the oxygen atom giving the oxygen of the carboxylic group a shared bond with the $\mathrm{Cu}^{2+}$ ions. In the expanded spectrum shown in Figure $6 \mathrm{~h}$, two characteristic peaks for the energy levels of $\mathrm{Cu} 2 \mathrm{p}_{1 / 2}(934.25 \mathrm{eV})$ and $\mathrm{Cu} 2 \mathrm{p}_{3 / 2}(954.15 \mathrm{eV})$ are visible [30]. In general, oxygen atoms and nitrogen atoms in CMCNF30-PEI have significant contributions to $\mathrm{Cu}^{2+}$ ion adsorption. The XPS spectra provided direct evidence of $\mathrm{Cu}^{2+}$ adsorption on CMCNF30-PEI via chemisorption. 


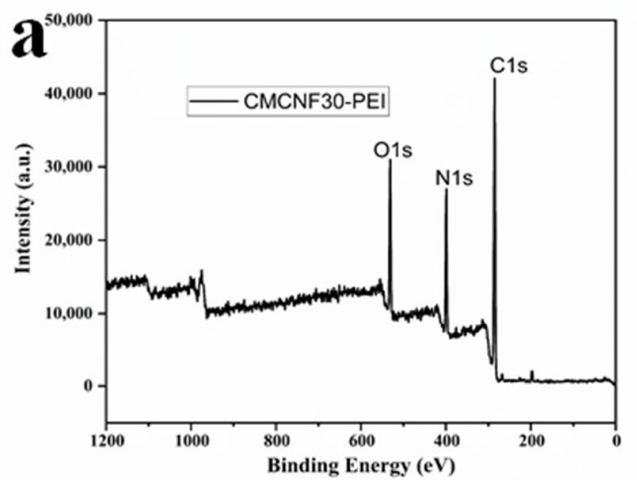

e

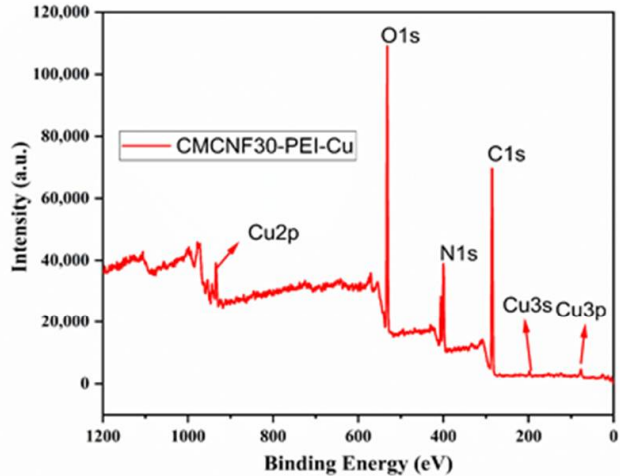

b

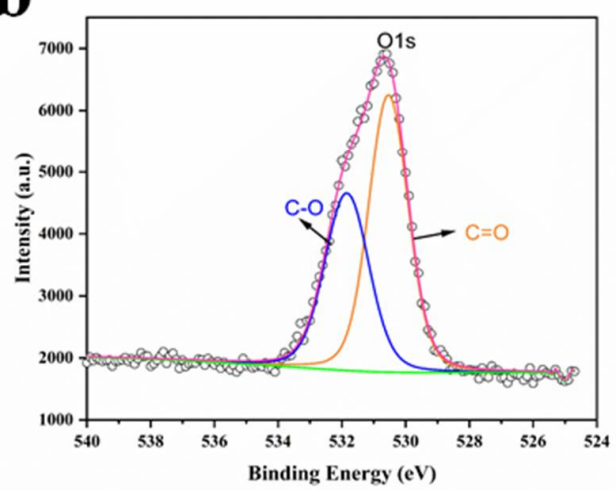

f
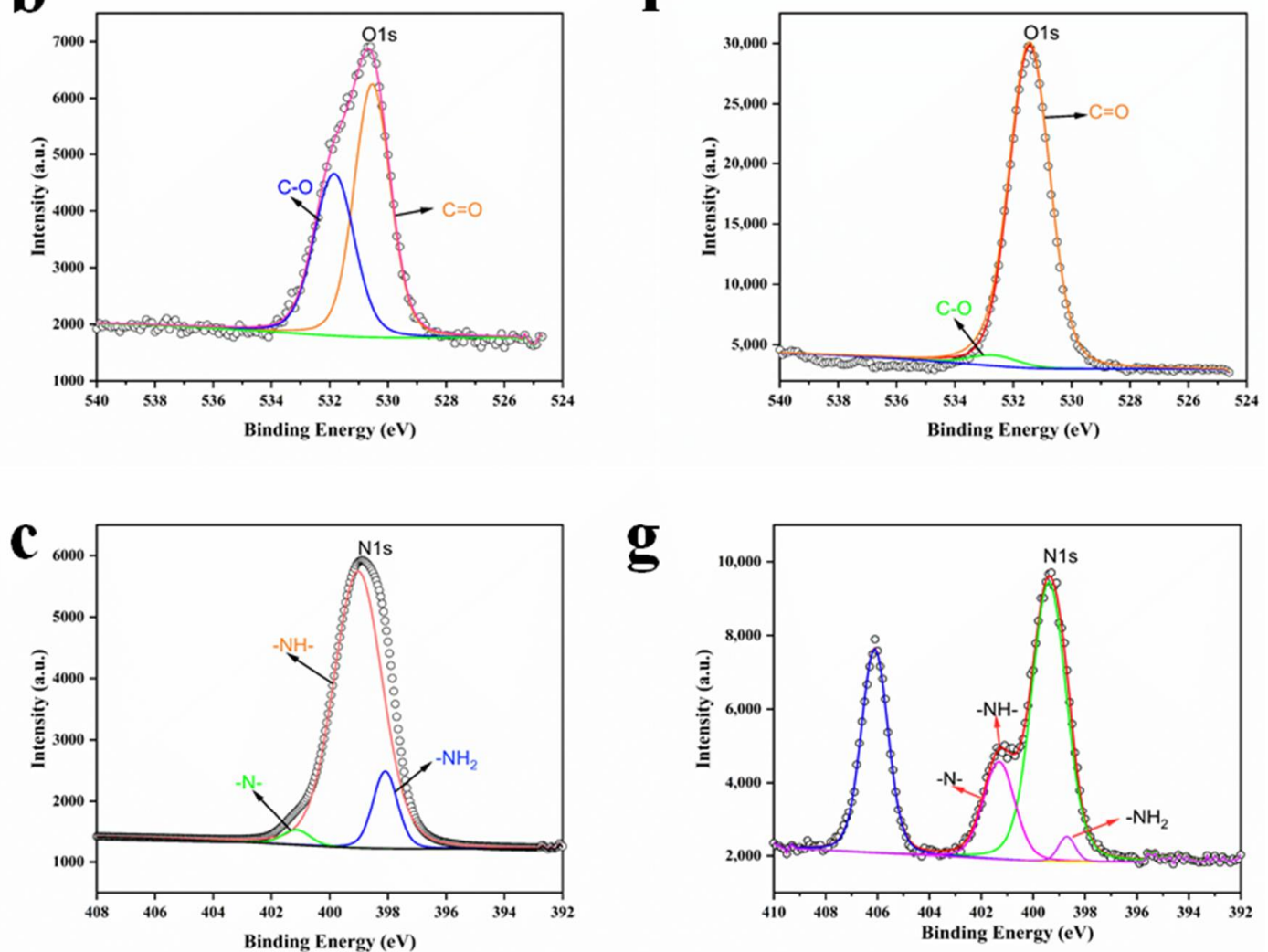

g

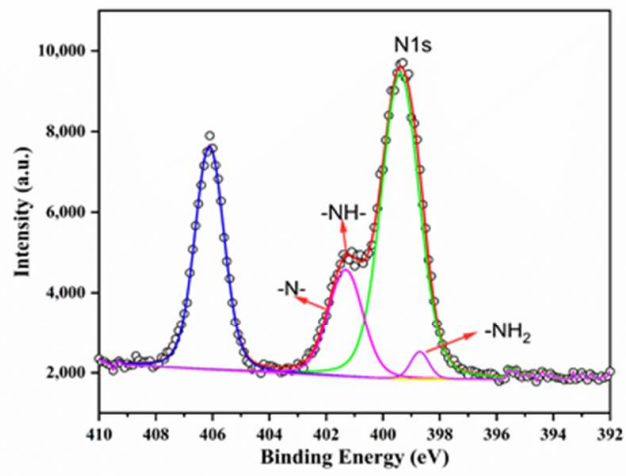

d

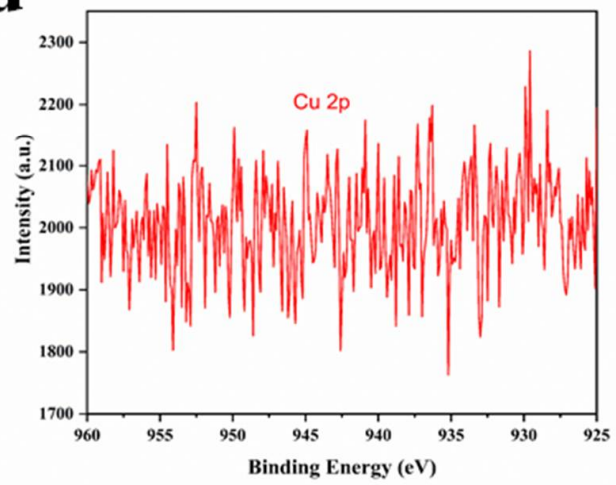

h

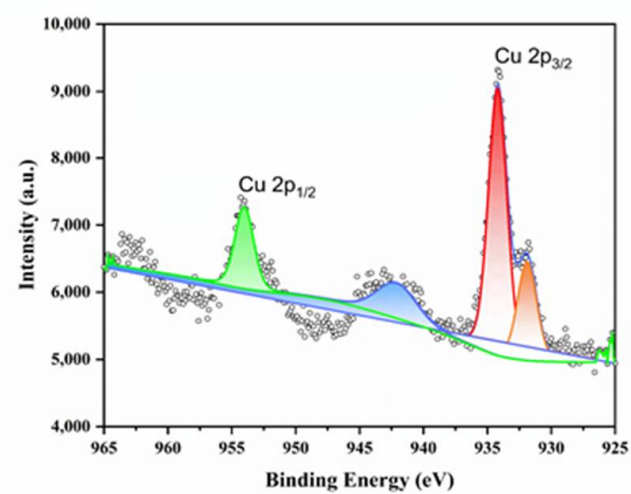

Figure 6. (a) Wide-scan XPS spectrum and (b-d) high-resolution core-level spectrum of CMCNF30PEI, (e) wide-scan XPS spectrum and (f-h) high-resolution core-level spectrum of CMCNF30-PEI after $\mathrm{Cu}^{2+}$ adsorption. 
The adsorption mechanism of the CMCNFs-PEI for $\mathrm{Cu}^{2+}$ derived from the data presented in the present study is shown in Figure 7. XPS results show that both $\mathrm{N}$ and $\mathrm{O}$ atoms have a certain effect on $\mathrm{Cu}^{2+}$. Among them, $-\mathrm{COOH}$ plays the role of electrostatic attraction, and functional groups such as $-\mathrm{NH}$ and $-\mathrm{NH}_{2}$ serve as a ligand for producing ligand-metal surface complexes, thus achieving the effect of $\mathrm{Cu}^{2+}$ removal.

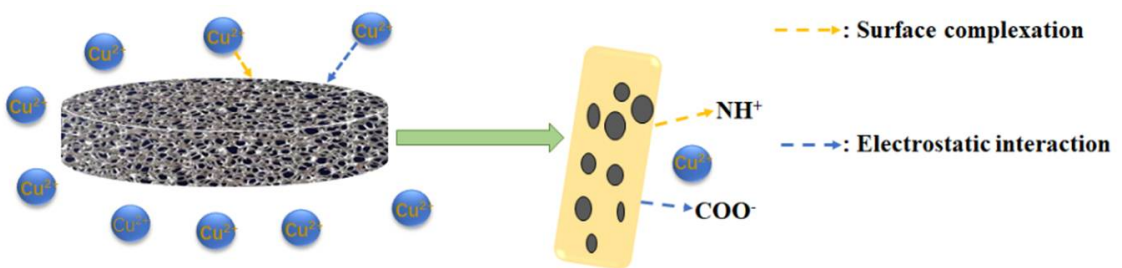

Figure 7. Schematic illustration of the adsorption mechanism of the CMCNFs-PEI.

\subsubsection{Desorption and Reusability}

The ideal aerogel should have high adsorption capacity and have good regeneration and recycling properties, which are an important index of the practical application of water remediation. After adsorbtion with $\mathrm{Cu}^{2+}$ (Figure 8a), as can be clearly seen, the internal structure remained 3D reticulated, but the channels became tense. From FTIR spectra (Figure 8b), CMCNF30-PEI aerogel showed that the positions of characteristic peaks related to amino and carboxyl groups changed after $\mathrm{Cu}^{2+}$ adsorption. In order to explore the recycling ability of CMCNF30-PEI, 0.05 M EDTA solution was used as the desorption agent. Figure $8 \mathrm{c}$ shows the performance of CMCNF30-PEI for $\mathrm{Cu}^{2+}$ adsorption during three cycles. Although the regeneration efficiency decreased slightly with the cycle time, it still retained $85 \%$ after three adsorption-desorption cycles, indicating the excellent recyclability and reusability of the developed aerogel. The stability test showed the excellent cycling ability of the current test, thus it can be applied to practical wastewater treatment.
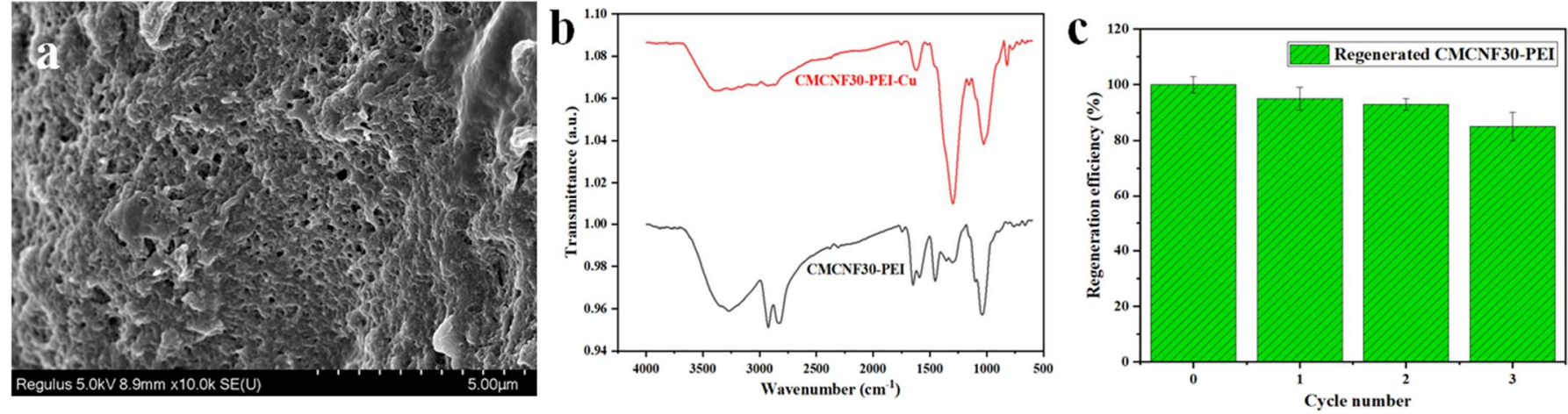

Figure 8. (a) SEM image of CMCNF30-PEI after adsorbed $\mathrm{Cu}^{2+}$. (b) FTIR spectra of CMCNF30-PEI aerogel and CMCNF30-PEI aerogel loaded with $\mathrm{Cu}^{2+}$. (c) Three adsorption cycles of CMCNF30-PEI aerogel for $\mathrm{Cu}^{2+}$ solution.

\subsubsection{Comparison with Reported Studies}

The final adsorption properties of CMCNF30-PEI were evaluated and presented in Table 5 for comparison with reported data. The maximum adsorption capacity of CMCNF30-PEI for $\mathrm{Cu}^{2+}$ can reach $588.26 \mathrm{mg} / \mathrm{g}$; 3-dialdehyde nano-fibrillated cellulose (DNFCs), TO-CNF/PVA/PEI nanoparticles, $\mathrm{Fe}_{3} \mathrm{O}_{4} @$ zeolite $\mathrm{NaA}$ and composite from cellulose nanocrystals of Almond Prunus dulcis shell (CPCNCs) are much higher. Having excellent cycling performance as well, CMCNF30-PEI may play an important role in practical water treatment. 
Table 5. Comparison of $\mathrm{Cu}^{2+}$ adsorption capacity of different materials.

\begin{tabular}{cccc}
\hline Adsorbent & $\begin{array}{c}\text { Adsorption Capacity } \\
(\mathbf{m g} / \mathbf{g})\end{array}$ & Cycle Times & Ref \\
\hline DNFCs & 29.52 & 3 & {$[22]$} \\
\hline TO-CNF/PVA/PEI nanoparticles & 156.8 & & {$[16]$} \\
\hline $\mathrm{Fe}_{3} \mathrm{O}_{4}$ @zeolite NaA & 86.54 & 4 & {$[31]$} \\
\hline CPCNCs & 131.16 & 3 & This work \\
\hline CMCNF30-PEI & 614.48 & $33]$ \\
\hline
\end{tabular}

\section{Conclusions}

In summary, we demonstrated a facile and novel CMCNFs-PEI adsorbent that has a high adsorption capacity for $\mathrm{Cu}^{2+}$. Compared with pure $\mathrm{CMCNF}$, the hydrophilicity of CMCNF-PEI obviously decreased, and this led to an appearance of a 3D network structure. Remarkably, adsorption isotherm data revealed that the maximum adsorption capacity for $\mathrm{Cu}^{2+}$ was in the order: CMCNC30-PEI $(618.48 \mathrm{mg} / \mathrm{g})>$ CMCNF20-PEI $(528.36 \mathrm{mg} / \mathrm{g})$ $>$ CMCNF10-PEI ( $307.43 \mathrm{mg} / \mathrm{g})$. Kinetic studies showed that the adsorption process of $\mathrm{Cu}^{2+}$ on CMCNFs-PEI was more likely to be modeled by pseudo-second-order equation. The adsorption mechanism of $\mathrm{Cu}^{2+}$ might be attributed to the active sites (carboxyl, amino groups) on the surface of CMCNF30-PEI. In addition, EDTA solution can regenerate CMCNF30-PEI, with the adsorption capacity still retained at $85 \%$ after three cycles. This work provides a facile and novel method for preparing the $\mathrm{CMCNFs-based} \mathrm{Cu}^{2+}$ adsorbent.

Author Contributions: R.S.: Conceptualization, Methodology, Writing-original draft. Y.C.: Software. D.W.: Visualization, D.Y.: Supervision. Q.D.: Data curation, Writing-review \& editing. R.L.: Resources. C.W.: Project administration, Funding acquisition, Formal analysis. All authors have read and agreed to the published version of the manuscript.

Funding: This article was financially supported by the National Key R\&D Program of China (2017YFB0307900) and the Foundation (No. ZZ20200107) of State Key Laboratory of Biobased Material and Green Papermaking, Qilu University of Technology, Shandong Academy of Sciences, Natural Science Foundation of Shandong Province, China (ZR2021QC158).

Conflicts of Interest: The authors declare no conflict of interest.

\section{References}

1. Na Kim, H.; Ren, W.X.; Kim, J.S.; Yoon, J. Fluorescent and colorimetric sensors for detection of lead, cadmium, and mercury ions. Chem. Soc. Rev. 2011, 41, 3210-3244. [CrossRef]

2. Chen, Q.; Zheng, J.; Wen, L.; Yang, C.; Zhang, L. A multi-functional-group modified cellulose for enhanced heavy metal cadmium adsorption: Performance and quantum chemical mechanism. Chemosphere 2019, 224, 509-518. [CrossRef] [PubMed]

3. Amarasinghe, B.; Williams, R.A. Tea waste as a low cost adsorbent for the removal of $\mathrm{Cu}$ and Pb from wastewater. Chem. Eng. J. 2007, 132, 299-309. [CrossRef]

4. Fu, F.; Wang, Q. Removal of heavy metal ions from wastewaters: A review. J. Environ. Manag. 2011, 92, 407-418. [CrossRef] [PubMed]

5. Shen, C.; Zhao, Y.; Li, W.; Yang, Y.; Liu, R.; Morgen, D. Global profile of heavy metals and semimetals adsorption using drinking water treatment residual. Chem. Eng. J. 2019, 372, 1019-1027. [CrossRef]

6. Qin, H.; Hu, T.; Zhai, Y.; Lu, N.; Aliyeva, J. The improved methods of heavy metals removal by biosorbents: A review. Environ. Pollut. 2019, 258, 113777. [CrossRef] [PubMed]

7. Musarurwa, H.; Tavengwa, N.T. Application of carboxymethyl polysaccharides as bio-sorbents for the sequestration of heavy metals in aquatic environments. Carbohydr. Polym. 2020, 237, 116142. [CrossRef]

8. Thomas, B.; Raj, M.C.; Athira, K.B.; Rubiah, M.H.; Joy, J.; Moores, A.; Drisko, G.L.; Sanchez, C. Nanocellulose, a Versatile Green Platform: From Biosources to Materials and Their Applications. Chem. Rev. 2018, 118, 11575-11625. [CrossRef] [PubMed]

9. Ma, H.; Hsiao, B.S.; Chu, B. Ultrafine Cellulose Nanofibers as Efficient Adsorbents for Removal of UO22+ in Water. ACS Macro Lett. 2011, 1, 213-216. [CrossRef]

10. Fan, X.-M.; Yu, H.-Y.; Wang, D.-C.; Mao, Z.-H.; Yao, J.; Tam, K.C. Facile and Green Synthesis of Carboxylated Cellulose Nanocrystals as Efficient Adsorbents in Wastewater Treatments. ACS Sustain. Chem. Eng. 2019, 7, 18067-18075. [CrossRef] 
11. Li, S.-S.; Song, Y.-L.; Yang, H.-R.; An, Q.-D.; Xiao, Z.-Y.; Zhai, S.-R. Carboxymethyl cellulose-based cryogels for efficient heavy metal capture: Aluminum-mediated assembly process and sorption mechanism. Int. J. Biol. Macromol. 2020, 164, 3275-3286. [CrossRef] [PubMed]

12. Lian, Z.; Li, Y.; Xian, H.; Ouyang, X.-K.; Lu, Y.; Peng, X.; Hu, D. EDTA-functionalized magnetic chitosan oligosaccharide and carboxymethyl cellulose nanocomposite: Synthesis, characterization, and $\mathrm{Pb}(\mathrm{II})$ adsorption performance. Int. J. Biol. Macromol. 2020, 165, 591-600. [CrossRef] [PubMed]

13. Xu, X.; Ouyang, X.-K.; Yang, L.-Y. Adsorption of $\mathrm{Pb}(\mathrm{II})$ from aqueous solutions using crosslinked carboxylated chitosan/carboxylated nanocellulose hydrogel beads. J. Mol. Liq. 2020, 322, 114523. [CrossRef]

14. Cheng, Y.; Lu, L.; Zhang, W.; Shi, J.; Cao, Y. Reinforced low density alginate-based aerogels: Preparation, hydrophobic modification and characterization. Carbohydr. Polym. 2012, 88, 1093-1099. [CrossRef]

15. Li, J.; Zuo, K.; Wu, W.; Xu, Z.; Yi, Y.; Jing, Y.; Dai, H.; Fang, G. Shape memory aerogels from nanocellulose and polyethyleneimine as a novel adsorbent for removal of $\mathrm{Cu}(\mathrm{II})$ and $\mathrm{Pb}(\mathrm{II})$. Carbohydr. Polym. 2018, 196, 376-384. [CrossRef] [PubMed]

16. Si, R.; Wu, C.; Yu, D.; Ding, Q.; Li, R. Novel TEMPO-oxidized cellulose nanofiber/polyvinyl alcohol/polyethyleneimine nanoparticles for $\mathrm{Cu}^{2+}$ removal in water. Cellulose 2021, 28, 10999-11011. [CrossRef]

17. Li, H.; Wang, Y.; Ye, M.; Zhang, X.; Zhang, H.; Wang, G.; Zhang, Y. Hierarchically porous poly(amidoxime)/bacterial cellulose composite aerogel for highly efficient scavenging of heavy metals. J. Colloid Interface Sci. 2021, 600, 752-763. [CrossRef]

18. Xing, H.T.; Chen, J.H.; Sun, X.; Huang, Y.H.; Su, Z.B.; Hu, S.R.; Weng, W.; Li, S.X.; Guo, H.X.; Wu, W.B.; et al. NH2-rich polymer/graphene oxide use as a novel adsorbent for removal of $\mathrm{Cu}$ (II) from aqueous solution. Chem. Eng. J. 2015, 263, 280-289. [CrossRef]

19. Zhang, X.; Elsayed, I.; Navarathna, C.; Schueneman, G.T.; Hassan, E.B. Biohybrid Hydrogel and Aerogel from Self-Assembled Nanocellulose and Nanochitin as a High-Efficiency Adsorbent for Water Purification. ACS Appl. Mater. Interfaces 2019, 11, 46714-46725. [CrossRef]

20. Zhang, Z.; Wu, C.; Ding, Q.; Yu, D.; Li, R. Novel dual modified alkali lignin based adsorbent for the removal of Pb2+ in water. Ind. Crop. Prod. 2021, 173, 114100. [CrossRef]

21. Zhu, Y.; Wu, C.; Yu, D.; Ding, Q.; Li, R. Tunable micro-structure of dissolving pulp-based cellulose nanofibrils with facile prehydrolysis process. Cellulose 2021, 28, 3759-3773. [CrossRef]

22. Lei, Z.; Gao, W.; Zeng, J.; Wang, B.; Xu, J. The mechanism of Cu (II) adsorption onto 2,3-dialdehyde nano-fibrillated celluloses. Carbohydr. Polym. 2019, 230, 115631. [CrossRef] [PubMed]

23. Wang, N.; Ouyang, X.-K.; Yang, L.-Y.; Omer, A.M. Fabrication of a Magnetic Cellulose Nanocrystal/Metal-Organic Framework Composite for Removal of $\mathrm{Pb}(\mathrm{II})$ from Water. ACS Sustain. Chem. Eng. 2017, 5, 10447-10458. [CrossRef]

24. Tang, F.; Yu, H.; Abdalkarim, S.Y.H.; Sun, J.; Fan, X.; Li, Y.; Zhou, Y.; Tam, K.C. Green acid-free hydrolysis of wasted pomelo peel to produce carboxylated cellulose nanofibers with super absorption/flocculation ability for environmental remediation materials. Chem. Eng. J. 2020, 395, 125070. [CrossRef]

25. Tang, J.; Song, Y.; Zhao, F.; Spinney, S.; da Silva Bernardes, J.; Tam, K.C. Compressible cellulose nanofibril (CNF) based aerogels produced via a bio-inspired strategy for heavy metal ion and dye removal. Carbohydr. Polym. 2019, 208, 404-412. [CrossRef] [PubMed]

26. Qin, F.; Fang, Z.; Zhou, J.; Sun, C.; Chen, K.; Ding, Z.; Li, G.; Qiu, X. Efficient Removal of Cu ${ }^{2+}$ in Water by Carboxymethylated Cellulose Nanofibrils: Performance and Mechanism. Biomacromolecules 2019, 20, 4466-4475. [CrossRef]

27. Li, J.; Xu, Z.; Wu, W.; Jing, Y.; Dai, H.; Fang, G. Nanocellulose/Poly(2-(dimethylamino)ethyl methacrylate)Interpenetrating polymer network hydrogels for removal of $\mathrm{Pb}(\mathrm{II})$ and $\mathrm{Cu}(\mathrm{II})$ ions. Colloids Surfaces A Physicochem. Eng. Asp. 2018, 538, 474-480. [CrossRef]

28. Rodrigues, F.H.; Magalhaes, C.E.D.C.; Medina, A.L.; Fajardo, A.R. Hydrogel composites containing nanocellulose as adsorbents for aqueous removal of heavy metals: Design, optimization, and application. Cellulose 2019, 26, 9119-9133. [CrossRef]

29. Mo, L. 3D multi-wall perforated nanocellulose-based polyethylenimine aerogels for ultrahigh effcient and reversible removal of $\mathrm{Cu}(2+)$ ions from water. Chem. Eng. J. 2019, 378, 122157. [CrossRef]

30. Cao, Y.; Qian, X.; Zhang, Y.; Qu, G.; Xia, T.; Guo, X.; Jia, H.; Wang, T. Decomplexation of EDTA-chelated copper and removal of copper ions by non-thermal plasma oxidation/alkaline precipitation. Chem. Eng. J. 2019, 362, 487-496. [CrossRef]

31. Cao, J.; Wang, P.; Shen, J.; Sun, Q. Core-shell $\mathrm{Fe}_{3} \mathrm{O}_{4} @$ zeolite $\mathrm{NaA}$ as an Adsorbent for Cu ${ }^{2+}$. Materials 2020, 13, 5047. [CrossRef] [PubMed]

32. Maaloul, N.; Oulego, P.; Rendueles, M.; Ghorbal, A.; Díaz, M. Biopolymer composite from cellulose nanocrystals of almond (Prunus dulcis) shell as effective adsorbents for $\mathrm{Cu}^{2+}$ ions from aqueous solutions. J. Environ. Chem. Eng. 2021, 9, 105139. [CrossRef] 